\title{
Towards an Understanding of Side-Lining Environmental Sustainability in Formula E: Traditional Values and the Emergence of eSports
}

\author{
By Timothy Robeers* \\ Hilde Van Den Bulck ${ }^{\dagger}$
}

The electric racing series of Formula $E$ is the motor sport's governing body's latest initiative to promote and generate more sustainable transport. The question remains however if its attempt to go "green" is simply a smokescreen for yet another commodity spectacle. By means of a mixed method approach, this study investigates the selfrepresentation of Formula $E$ in relation to environmental sustainability and factors of commodification. Results suggest that Formula E makes use of marketing and educational advantages that come with adopting an environmentally sustainable approach to motor sport. Although this means Formula $E$ does not escape the grasp of commodification, much like Formula One, it also implies that, probably for the first time ever, motor sport has taken a significant initiative to become more environmentally and socially sustainable.

Keywords: Commodification, Environmental Sustainability, Formula E, Mixed Method Analysis, Political Economy, Representation

\section{Introduction: Motor Sport Meets Environmental Sustainability}

Environmental sustainability (hereafter: ES), described in the United Nations' Brundtland report as developments that meet the needs of the present whilst ensuring future generations meet theirs (United Nations 1988), for several decades has been high on the agenda of governments, international and social-profit organizations and industries alike, including those related to the motoring industry. As such, the Fédération International de l'Automobile (FIA), which functions as motor sport's governing body, puts great emphasis on its efforts to monitor and improve the environmental, socio-economic and safety aspects of motor sport and motoring in general (Dingle 2009). Besides actively participating in the United Nation's Sustainable Development Agenda and in the ongoing global debate on climate change, where it cooperates with the Global Fuel Economy Initiative, the FIA makes use of its connections with motor sport to help promote its environmental campaigns. Examples include the "FIA Action for Environment" and the "Make Cars Green Campaign" whereby Formula One drivers endorsed the latter campaign generating worldwide exposure (Fédération Internationale de l'Automobile 2016). This can be considered a significant development in the attitude of motor sport regarding its relationship with the natural environment. It

*Research Member of Staff (Bap) and Phd Student, Research Group: Media, Policy and Culture (Mpc) and Department of Communication Sciences, University of Antwerp, Belgium.

†Professor and Head of Communication, Drexel University, USA. 
acknowledges motor sport's need to manage and market itself as sustainable, in line with the wider acceptance of changed environmental circumstances globally (Dingle 2009).

A key step in this regard is the FIA's part in developing Formula E, a fully electric racing series which is meant to serve as a platform for research and development, education and promotion of more environmentally and socially sustainable modes of transport (Formula E 2015). Formula $\mathrm{E}$ is an annual, single seater racing series taking place in various cities around the world, involving big name drivers and teams. The electric nature of the cars means lower noise levels and carbon dioxide emissions, allowing races to take place on temporary city center circuits and audiences of all ages to attend races and (potentially) learn about the future and benefits of electric cars. However, as a new concept, what Formula E brings in innovation, it also brings in uncertainty. Indeed, ES has not been part of fan values traditionally associated with motor racing (Roy et al. 2010). This creates considerable challenges for Formula E to establish itself both as a relevant and (commercially and otherwise) successful motor sport series and as an example of ES in motor sport. This article aims to understand how the organization of Formula $\mathrm{E}$ has chosen to represent itself in relation to ES by means of an analysis of its self-representation on its official website. To this end, it first establishes a theoretical framework, combining insights from both a marketing and a political economy approach to corporate social responsibility (hereafter: CSR) and ES in general and in motor sport in particular. It further develops a framework to understand self-representation. Next, it operationalizes the main and subresearch questions by determining the sample for which a mixed method approach is designed, after which the findings are presented and discussed.

\section{Environmental Sustainability and Corporate Social Responsibility}

Environmental sustainability (ES) has become an integral part of corporate social responsibility (CSR), yet due to the significant academic interest and the variety of theories, for example the triple bottom line approach and stakeholder theory, on the topic, no exclusive definition exists. The European Commission (2011) defines it as:

The responsibility of enterprises for their impacts on society [...] enterprises should $[\ldots]$ have a process in place to integrate social, environmental, ethical human rights and consumer concerns into their business operations and core strategy in close cooperation with their stakeholders.

Another definition by Mohr et al. (2001) considers ES to be the initiative to minimize or eliminate harmful effects on society with the aim to create long term sustainability in businesses and communities (Mohr et al. 2001). In a study on CSR practices by multinational corporations, research has revealed that almost all companies provide an environmental policy and around $80 \%$ provides 
environmental reporting (Karlsen 2011). Particularly the latter is relatively easily exercised and allows corporations to enhance their image (Karlsen 2011).

This growing emphasis on ES is driven both by the possibility of creating new markets through ES and, institutionally, by government policies and regulation (Trendafilova et al. 2013). The growing relevance of ES extends to sport that, according to Smith and Westerbeek (2004), is becoming increasingly "green" by adopting ES in CSR strategies. They identify two main reasons: firstly, motor- and other types of sport are responsible for environmental damage and are therefore unavoidably "being called to ransom by the community at large" (Smith and Westerbeek 2004: 138). Secondly, it is clear that "industries and governments have come to understand the marketing and education potential of green sport" (Smith and Westerbeek 2004: 138). Adopting ES in CSR provides sport with certain advantages. Not only does it satisfy stakeholders, it can generate brand and image enhancement, and (thus) bring in new fans. More so, it reduces the carbon footprint of the sport and its associated activities, and helps raise environmental awareness with a broad audience. Such associations that accompany the adoption of ES in CSR are representative of what is known as "green marketing" (Cox 2012: 286).

Today, marketing motor sport involves considering how to make the sport genuinely sustainable in terms of the environment and, in some cases, to make ES the core ethos (Dingle 2009). As such, ways in which motor sport organizations embrace and enact environmental CSR range from rather limited activities such as planting trees or encouraging public transportation to more substantial initiatives such as engaging in long term partnerships with environmentally minded businesses or opting for solar and/or wind power (Trendafilova et al. 2013: 299). Yet, in the case of Formula One, research (Karlsen 2011) has shown that the brand has become so popular and well established that it has no need to take CSR and ES very seriously. Another study by Fairley et al. (2011) looked into ES as part of the 2008 Australian Formula One Grand Prix's triple bottom line, the latter referring to organizations and their need to consider socio-economic and environmental impact of their business practices. Yet, the study did not include to what extent the organization of Formula One undertook (marketing) measures to improve sustainability and enhance its image. Such a lack of academic focus on ES within the sport as a whole exists, at least in part, because efforts to improve sustainability in motor sport are rare. Yet, one other example of a motor sport series worth mentioning is the WEC (World Endurance Championship) which includes the 24 hours of Le Mans race and encourages the development and use of hybrid technology for endurance racing. Regarding Formula E, however, the relationship to ES in CSR seems more self-evident, given that it is presented as a platform for understanding and promotion of electric motoring as a more environmentally and socially sustainable mode of transport (cf. supra). Consequently, this article aims to provide an answer to the question how and to what extent Formula E presents itself first and foremost as an example of ES in motor sport. 


\section{A More Critical View on Environmental Sustainability Marketing Strategies}

ES and wider CSR are part of the marketing of motor sport, yet it has also attracted interest from a political economy perspective that positions these strategies and their relationship to motor sport within "power relations, that mutually constitutes the production, distribution and consumption of resources" (Mosco 2009: 25). An earlier study into motor sport and ES is Hassan and O'Kane's (2011) analysis of the Paris to Dakar Rally and its impact on the development of ES as part of CSR within auto sport. They found that the Rally's environmental CSR project, aimed at supporting local African communities in the countries the rally visited was depicted by some as a smokescreen, meant to divert criticism of possible dangers or lack of ES away from the Rally. This more critical approach suggests a certain practice of "greenwashing", a form of misleading information released by an organization with the aim of presenting itself as having an environmentally sustainable public image (Cox 2012: 286). Like the Paris Dakar Rally and Formula One, corporations invoke ideals to describe themselves as morally legitimate, when mainly pursuing economic self-interest. As such, greenwashing is not just a form of misleading information released by an organization with the aim of presenting itself as having an environmentally sustainable public image (Cox 2012: 286). As Miller (2016) reveals in his study on greenwashing practices in Formula One and FIFA, greenwashing can be a sporting organization's way of combining a set of goals, namely a quest for profit unhampered by regulation, the aim to be morally legitimate and an urge to meddle in everyday life. Based on this, this article aims to provide an answer to the question if and to what extent ES as part of CSR of Formula E can be considered a form of greenwashing. Such greenwashing has been shown in wider contexts to be related to commercialization or the socio-economic process of transforming a sport into a business (Sturm 2011) as well as commodification or process by which goods and services with high use value are transformed into marketable products as commodities (Mosco 2009). With respect to the latter, in motor sport this ranges from clothes ware to larger paraphernalia and even drivers as consumer objects (Sturm 2011). Indeed, commodification is also known to extend to the environment, to environmental sustainability and derivatives such as ecotourism and, indeed, professional sport (Dorsey et al. 2004). Furthermore, the promotion of commodity consumption as environmentally sustainable is known to be associated with greenwashing (Cox and Pezzullo 2015). Another question this article aims to provide an answer to is how and to what extent Formula E contributes to the commodification of ES.

\section{Factors of Commodification in Motor Sport}

Professional sport has a long history of producing commodities such as live events in order to generate revenue (Dart 2014). As such, Formula One - as the pinnacle of motor racing - has been shown to function as a well-oiled homogenous global commodity spectacle (see e.g. Sturm 2014). It does so, 
according to Sturm (2014) by using commodified objects or factors such as celebrities and glamourous lifestyles that are aimed specifically at mass consumption and that can be easily reproduced. Cox (2012) suggests two more factors of commodification, i.e. games and advertisements.

The newly established Formula E and its relationship to ES becomes of particular interest as it begs the next question this article will aim to answer, namely how the commodified factors often associated with motor sport in general relate to (i.e. shape and affect and/or are affected and shaped by) ES in Formula $E$. We therefore address each of the factors, namely glamour, celebrities, gamification and advertisements and their relation to ES in motor sport.

\section{Glamour}

This commodified factor in motor sport has been traced back to key components such as "fast cars, expensive kit, global jet-setting and beautiful women with spray-on smiles" that function as trophies and adornments (Turner 2005: 205, Sturm 2014). Despite being firmly rooted in top end motor sport series such as Formula One, commodification through glamour and its subsequent components is not in itself associated with an ES approach, as the latter has long been seen to restrict motor sport values such as speed of racing and the reputation of the series (Roy et al. 2010). This begs the following question this article aims to provide an answer to which is if and how Formula E bridges the seemingly opposing values of glamour in motor sport with those of ES, and whether it thus contributes to the commodification of ES.

\section{Celebrities}

Celebrities are considered as hyper-commodities: at the same time vehicles for the presentation of commodities and a tradable commodity themselves (Rojek 2006). Yet, since the turn of the century, they increasingly perform functions as endorsers of social and environmental causes, so much so that it has now become part of a celebrity's job description (Lester 2010, Cox 2012, Panis and Van den Bulck 2014). This celebrity engagement extends to issues regarding the environment, from celebrities such as Keira Knightley driving ES cars to celebrity activists such as Leonardo DiCaprio addressing politicians at environmental world summits. Consequently companies have integrated celebrities in their media strategy for the implementation of environmental CSR as a means to strengthen and mobilize support (Lester 2010). Consequently, this article aims to provide an answer to the question how and to what extent Formula E employs celebrities in the promotion of its ES project.

\section{Gamification}

Crabbe and Brown (2004) confirm that it is of vital importance to maintain the ability to sell sports as an authentic or nostalgic (viewing) experience for audiences. On the other hand, it is becoming increasingly imperative for both 
(motor) sporting organizations and media alike to be on top of emerging popular trends. One such emerging trend in (motor) sport can be found in the world of competitive video gaming, namely eSports or more specifically "games that resemble conventional sports insofar as they have superstars, [...], fans, uniforms, comeback and upsets. [...] But all the action in [eSports] occurs online, and the contestants hardly move" (Segal 2014, para. 6.). As such, Formula E has embraced eSports to allow (amateur) audiences to connect and engage with the sport more closely than ever before. For example, it has achieved this for the first time in 2017 through setting up a virtual championship alongside the 'real world' Formula E championship whereby amateur and professional gamers can compete for what was at that time the largest ever eSports prize pot totalling one million dollars (Formula E 2015). Subsequently, the final eRace in Las Vegas generated extensive additional media coverage for Formula $\mathrm{E}$ through both mainstream news media channels as well as the popular online eSports broadcasting channel twitch.tv (Formula E 2015). The application of such games is commonly referred to as gamification. Beyond eSports, gamification can also use existing elements such as a website or other non-game context, and introduces game design elements with an aim to motivate participation and engagement, thus adding value to an organization (Deterding et al. 2011). Robert Cox (2012) reveals that, although the technique was initially used exclusively for commercial marketing purposes, gamification is increasingly used in environmental interests with the concept being ideally suited for people to join in environmental actions to the extent that it now even carries value as a commodity. He goes on to say that the internet and social media are the tools used most often in environmental gamifying, such as for example Carbonrally.com, a challenge where users team up, compete and interact via twitter to save the most energy and reduce the impact of climate change (Cox 2012). In the case of Carbonrally.com, the commodification of ES consequently brings with it an educational effect on users. This raises another question this article will aim to answer, namely if the gamification of ES in Formula E leads to the commodification of ES or whether it also serves an educational purpose.

\section{Advertising}

A final factor often associated with the commodification of ES is advertising (Van Couvering 2004). Particularly advertisements featuring ES elements, known as "green advertising", have become part and parcel of the communication strategy related to CSR and can be seen in advertising for a wide range of consumer goods and services. Car manufacturer GM, for example, advertised a new truck set against a forest with sunlight gleaming through accompanied by the caption "our respect for nature goes beyond just giving you an excellent view of it" and mentioned that it had made a "sizeable contribution to The Nature Conservancy" (Switzer 1997: 130, Cox 2012: 287). Such green advertising has also permeated the world of sports, including motor sport, and is often accompanied by so-called "eco" or "green" labels, display advertisements, listings, corporate logos and partner/sponsorship information denoting the ES characteristics, thus revealing the process of commodification (Corbett 2006, Cox 
2012: 287). As a result, this article aims to provide an answer to the question if and to what extent advertisements, corporate logos, and sponsorship contribute to the commodification of ES in Formula E.

\section{(Self-) Representation}

Mass media and new media play an important role in the process of commodification throughout the economy because they represent ideal sites of commodity production (Mosco 2009). The Internet, in particular, as a channel for communication is a primary source of credible information on sustainability in general (Russo et al. 2012). In relation to (self-) representation and sporting organizations, Haase-Reed et al. (2007) state that control over the former by the latter occurs most often by means of a website as this presents one of the easiest tools for an organization to choose its own organizational identity and to market itself. Such a digital storefront further helps to circumvent potential gatekeeping functions of the media (Haase-Reed et al., 2007). What is more, websites contain both textual and visual information, including advertisements, logos and labels, and this information is crucial to understand the daily workings of an organization (Jakubowska 2011). This is of particular importance considering that representation, as a key component of the process through which meaning is created, involves "the use of language, of signs and images" (Hall et al. 2013: 1). As such, websites provide an excellent basis to study the self-representation of an organization and the role of certain key factors such as ES in this selfrepresentation. As such, this article aims to understand the self-representation of Formula E, the position of ES in this and the potential commodification of ES as a result hereof, by means of a (self-) representational analysis of the official website of Formula $E$.

\section{Research Set-Up}

To answer these research questions, we analyzed the website of Formula E (Formula E 2015) during its inaugural season of 2014-15, in particular as it appeared online on 10 May 2015, the day after the Monaco Eprix. This particular moment was chosen because it is the only Formula $\mathrm{E}$ race that takes place on a track also used by Formula One, increasing potential influences from Formula One. It was assumed that in the inaugural season, the self-representation by Formula E on its website would have been carefully considered and implemented, while the inclusion of race results allowed for an insight into the nature of "regular" updates. NCapture was used to scrape all pages of the website, which also allows for text to be accessible to perform keyword searches. This sampling method resulted in a total of 201 webpages and documents. 
Quantitative Content Analysis

Table 1. Categories and Subcategories

\begin{tabular}{|c|c|c|c|}
\hline \multirow{2}{*}{$\begin{array}{l}\text { Categories For } \\
\text { Analysis }\end{array}$} & \multicolumn{3}{|c|}{ Subcategories For Analysis } \\
\hline & & $\begin{array}{l}\text { Theory } \\
\text { Based }\end{array}$ & $\begin{array}{c}\text { Data } \\
\text { Based }\end{array}$ \\
\hline Document ID & $\begin{array}{c}\text { Number } \\
\text { Title } \\
\text { Location On Site } \\
\text { Type (E.G. Editorial) }\end{array}$ & $\begin{array}{l}X \\
X \\
X \\
X\end{array}$ & \\
\hline Banners & $\begin{array}{c}\text { Top (Website Navigation: Home, } \\
\text { News, Etc) } \\
\text { Middle -Vertical (FE Partnerships) } \\
\text { Bottom - Horizontal (Race Teams) }\end{array}$ & $\mathrm{X}$ & $\begin{array}{l}X \\
X\end{array}$ \\
\hline Advertisements & $\begin{array}{c}\text { Name/ Description } \\
\text { Obvious Link With Formula E } \\
\text { Notion Of ES Presence } \\
\text { Audience Engagement }\end{array}$ & $\begin{array}{l}X \\
X\end{array}$ & $\begin{array}{l}X \\
X\end{array}$ \\
\hline Celebrities & $\begin{array}{c}\text { Presence } \\
\text { Identification } \\
\text { Name } \\
\text { Gender } \\
\text { Nationality } \\
\text { Industry } \\
\text { Celebrity Talk }\end{array}$ & $\begin{array}{l}X \\
X \\
X \\
X \\
X \\
X \\
X\end{array}$ & \\
\hline $\operatorname{Gam}(\mathrm{E}) /$ Ification & $\begin{array}{c}\text { Name Of Game } \\
\text { Intended Audience } \\
\text { Competitive Character Of Game } \\
\text { Medium Used } \\
\text { Sort Of Game } \\
\text { Game Goals } \\
\text { Game Feedback } \\
\text { Corporate Backing } \\
\text { Formula E Link } \\
\text { ES Link }\end{array}$ & $\begin{array}{l}X \\
X \\
X \\
X \\
X \\
X \\
X\end{array}$ & $\begin{array}{l}X \\
X\end{array}$ \\
\hline $\begin{array}{l}\text { Goals And } \\
\text { Objectives }\end{array}$ & $\begin{array}{c}\text { ES Goals } \\
\text { Non-ES Goals } \\
\text { Specific Environmental Concerns } \\
\text { Specific Environmental Objectives }\end{array}$ & $\begin{array}{l}X \\
X \\
X \\
X\end{array}$ & $\mathrm{X}$ \\
\hline $\begin{array}{l}\text { Images And Body } \\
\text { Of Text }\end{array}$ & $\begin{array}{c}\text { Presence Of Video Graphic Images } \\
\text { Presence Of Editorial Image As } \\
\text { Advert } \\
\text { Main Image Theme } \\
\text { Text Main Theme } \\
\text { Similarity Main Image Theme - Text } \\
\text { Main Theme } \\
\text { Similarity Main Image Theme - } \\
\text { Webpage Title }\end{array}$ & $\mathrm{X}$ & $\begin{array}{l}X \\
X \\
X \\
X \\
X\end{array}$ \\
\hline Other Remarks & & & \\
\hline
\end{tabular}

Source: Author. 
To obtain a broad but systematic insight into the various aspects of the selfrepresentation and representation of ES offered through the website, the first step of the empirical study involved a quantitative analysis. To this end, we developed a set of categories and subcategories. Inspired by ethnographic-like approaches (Gläser and Laudel 2013, see also Altheide 1996), we combined the original development of categories based on insights from the literature with an adjustment and elaboration of the instrument based on insights gained during coding of a first set of research materials. As a result, we aimed for a more systematic and analytic quantitative approach while avoiding the rigidness of a codebook developed solely on categories derived from literature (Bryman 2012). Table 1 provides an overview of the main categories and subcategories as used for the process of coding and indicates whether a (sub-) category was based on literature theory or data.

The smallest unit of analysis for text was a set of sentences that created a meaningful segment, which usually included a number of sentences but in some instances just one or two. For visual material, the smallest unit of analysis was a single image. However, when a webpage consisted of a large compilation of image-only material such as the webpages under the section "gallery", images were analyzed in group. Advertisements were analyzed both for textual- and visual elements. After all webpages were coded, the data were entered in a matrix database to look for emerging patterns (Gläser and Laudel 2013). To ensure the validity of the coding results, $5 \%$ of the data were coded by a second coder, a random $\mathrm{PhD}$ student unprejudiced because unfamiliar with the research questions but briefed about and familiarized with the coding instructions and schedule. Krippendorf's alpha $(\alpha)$ came down to 0.811 suggesting good intercoder reliability (Krippendorf 2004).

\section{The Qualitative Connection: Thematic Analysis}

To complement the quantitative content analysis, we applied a more qualitative, critical thematic analysis of the data, following the idea of Hall et al. (2013:158) that groups of statements are combined to create a useable language to talk about things. This allowed for a more in-depth analysis of representations, thus contributing to a better understanding of power relations (Hall et al. 2013). To this end, we returned to the primary material, i.e. the webpages, noting themes as they emerged. We identified up to three main themes for each webpage. Based on this detailed analysis, we were able to combine themes "into wider thematic categories that would represent overall segments" on the website as well as make out inter-theme relations (Bryman 2012: 581). After completing each of the two research steps, the results were compared and contrasted to create a deeper understanding of the representation of ES and the wider self-representation of Formula E on its website. 


\section{Findings}

In what follows, we first describe the general layout of the webpages on the Formula E website, after which we address the result of the textual analysis and its implications, followed by a more in-depth qualitative and thematic analysis.

\section{Webpage Layout}

Figure 1 provides a generic example of a webpage on the Formula $\mathrm{E}$ website. The top of the webpage features a navigational banner (a) with buttons for access to the different website sections (e.g. news, results, sustainability) with the main webpage image (b) just below. Below the main image we find a text box (c) which contains the main textual content on the webpage. In addition, the section designated for textual content can also contain images and varies between webpages. On the right side of this is a section for advertisements (d) which are vertically positioned and function as links to the associated companies. These precede another vertical listing of Formula E partnered companies, (e) followed by a final, horizontal banner containing all Formula E teams (f).

Figure 1. Formula E Webpage Example

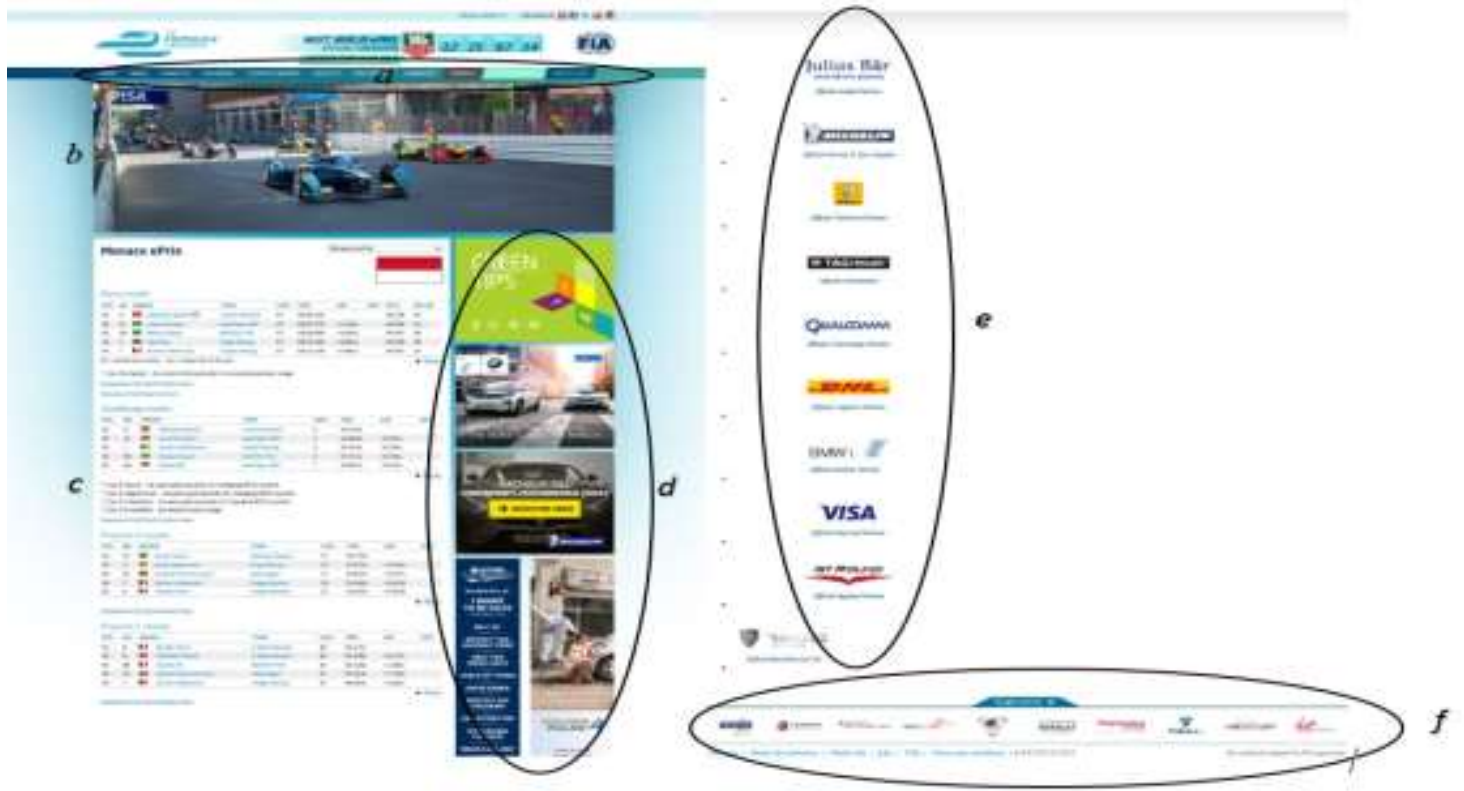

Source: FIA Formula E 2015

\section{Environmental Sustainability: Goals, Concerns and Objectives}

We first looked at three elements that are often associated with environmental advocacy, namely goals, objectives and concerns. Robert Cox (2012: 217) describes goals as "long term visions or values" and distinguishes them from objectives which are more detailed, immediate actions. The relevance of concerns then lies with the fact that private and individual concerns are usually translated 
into more public matters on a wide range of forums and, as such, are key in shaping the environmental public sphere (Cox 2012).

Table 2. (Non-) Environmental Goals, Concerns and Objectives

\begin{tabular}{|l|c|c|c|}
\hline ES GOALS & $\begin{array}{c}\text { Website } \\
\text { hits }\end{array}$ & ES CONCERNS & $\begin{array}{c}\text { Website } \\
\text { hits }\end{array}$ \\
\hline $\begin{array}{l}\text { Promoting clean energy and } \\
\text { sustainability }\end{array}$ & 14 & Carbon footprint & 9 \\
\hline $\begin{array}{l}\text { Education into feasibility of } \\
\text { electric mobility }\end{array}$ & 10 & Energy conservation & 7 \\
\hline $\begin{array}{l}\text { Increase the use of sustainable } \\
\text { mobility }\end{array}$ & 9 & Sustainable communities & 4 \\
\hline $\begin{array}{l}\text { Initiate changing the existing } \\
\text { image of motor sport as a } \\
\text { polluting sport }\end{array}$ & 7 & ES OBJECTIVES & \\
\hline $\begin{array}{l}\text { Improve image of electric } \\
\text { vehicles }\end{array}$ & 7 & Electric propulsion & 8 \\
\hline Reduce carbon footprint & 7 & Battery improvements & 7 \\
\hline $\begin{array}{l}\text { NON-ES GOALS } \\
\text { Maintaining traditional motor } \\
\text { sport values }\end{array}$ & 171 & $\begin{array}{c}\text { Nkilled drivers } \\
\text { Sotor sport heritage }\end{array}$ & 4 \\
\hline $\begin{array}{l}\text { Continuation of the Formula } \\
\text { One jet-set lifestyle }\end{array}$ & 99 & $\begin{array}{c}\text { Exotic and global locations } \\
\text { VIP guests }\end{array}$ & 40 \\
\hline $\begin{array}{l}\text { Provide information on the } \\
\text { proceedings of the sport }\end{array}$ & 93 & / & 19 \\
\hline Promote affiliated companies & 50 & $\begin{array}{l}\text { Tire Manufacturers } \\
\text { Car Manufacturers }\end{array}$ & 13 \\
\hline
\end{tabular}

Source: Author.

As Table 2 shows, 45 out of the 201 webpages contained a total of 90 hits, covering 20 different environmental goals. The top three hereof consisted of "promoting clean energy and sustainability" (14), "education into feasibility of electric mobility" (10), and "increase the use of sustainable mobility" (9), with fourth position being shared by three more goals, namely "initiate changing the existing image of motor sport as a polluting sport" (7), "improve image of electric vehicles" (7) and "reduce carbon footprint" (7).

To fully grasp the scope to which ES is presented on the website, we also looked at references of environmental concerns (35 hits) and suggested solutions or objectives (35 hits). The major concerns were "carbon footprint" (9), "energy conservation" (7) and "sustainable communities" (4), while the main suggested solutions included "electric propulsion" (8), "battery improvements" (7) and "awareness campaigns" (4). In line with environmental reporting as part of CSR by multinationals in (Karlsen 2011), these data thus suggest a fairly elaborate spread of these environmental parameters across the website. On the one hand, this could indicate a more genuine and profound environmental and social concern on behalf of the organization and the FIA than what has been the case in motor sport 
up until now. Indeed, many of the items raised are very much in line with larger contemporary efforts in sustainable development by multinationals (UNCTAD 2010) and assists in limiting criticisms of greenwashing (Simon 1995). Of course, a more critical interpretation of these data could read such practices of significantly applying these parameters as a means for image enhancement. Karlsen's (2011) claim that the use of environmental CSR by corporations is meant to be a win-win for business and society but is mostly still profit driven applies here to a certain extent as well. Indeed, as Formula E's CEO revealed:

[...] it makes sense for everybody in their own space to do something related to sustainability and to the environment. My space is motor-racing, so that comes first and, as a consequence, I want to do motor-racing in a cleaner way. (Swithinbank 2014).

Karlsen's (2011) claim is given further credit by means of the two most common non-ES goals, namely maintaining traditional motor sport values and continuation of the Formula One jet set lifestyle.

From ES, Other Initiatives, the Future and Technical Developments to Gamification

As part of Formula E's sustainability effort, we found initiatives such as Solar IMPULSE (flying a solar powered plane around the world to promote clean technologies), Earth Day (an annual, global event emphasizing environmental protection), R100 (companies that agree to strive using 100\% renewable energy), and eKarting (electric karting which expels no carbon dioxide or noise). In opting for these themes, Formula $\mathrm{E}$ associates its own sustainability efforts with those of others, thus legitimizing its efforts as part of a wider, contemporary and global trend. According to Corporate Watch (2006), this is often seen as corporate philanthropy because, as at least a pars of this will be stakeholder money, there needs to be a return on investment. Notwithstanding, this legitimization on the website is further linked to the theme of the future, suggesting Formula $\mathrm{E}$ is acting as a tool to positively add to a greener future by means of pushing the development of relevant and sustainable technologies as well as working with charities such as One Drop and Greenpower. Based on Corporate Watch's claims (2006), organizations such as, in this case, Formula E can create links with charities and causes with the aim of providing it with more market access as well as a more powerful message. More so Formula E's CSR aims strengthen its not yet full established brand identity, i.e. awareness and loyalty by appealing to customer's consciences and desires (Corporate Watch 2006: 12). For example, Formula E's cooperation with Greenpower involves stimulating future generations to get involved with sustainable engineering by erecting the Formula $\mathrm{E}$ school series where students build and race their electric race cars prior to Formula $\mathrm{E}$ races. This FE school series was also identified in the game analysis as one of five games including "Auction" (bidding on items for charity), "Prize Competition" (the best fan photograph wins), "Simulator competition" (on site Formula E race game for fans) and "Fanboost" (drivers selected by fans receive a power boost 
during the race). In case of the latter, audiences can be part of the change Formula E provides by having a theoretical possibility at changing the race's outcome by voting for a driver who may then receive a power boost activation period during the race. With Fanboost and by means of providing online racing simulator championships, Formula E taps into the emerging eSports scene. Out of all five games, only two revealed to have corporate backing: "FE school series" was powered by Michelin tyres and Greenpower, a UK trust aiming to advance education in sustainable education, and the "Simulator competition" was backed by VISA. The remaining games were created and supported by Formula E itself. Importantly, only "FE school series" and "Auction" made a clear reference to ES, the former by promoting sustainable engineering and Greenpower (and the kit it provided), the latter by making reference to charitable institutions such as the Prince Albert II of Monaco Foundation which is "dedicated to the protection of the environment and the promotion of sustainable development" (Formula E 2015). The educational range of Formula $\mathrm{E}$ is thus significantly aimed at children.

Further analysis revealed that social goals (e.g. promote sustainable technology, support charities) and social rewards (e.g. recognition as best school team) were by far the most common and also appeared in relation to the webpage's most prominent game, Fanboost. The latter could be used exclusively online while all other games were designed for use in the real world. Only the "Prize Competition" could be "played" trans-medially, i.e. combining online usage with real world usage. The Fanboost section of the website revealed no relationship to ES and was characterized by a distinctive lack of advertisements or partner logos. This indicates an exclusive emphasis on promoting motor racing and on increasing fan involvement and, consequently, hints at commodification of audiences and labour (Mosco 2009). This is because the use of voting results affects the actual race and fan data obtained through the Fanboost login might be used for further marketing purposes. In this sense, gamification in Formula $\mathrm{E}$ seems to primarily carry value as a commodity, despite a (limited) educational effect in terms of ES.

\section{Celebrities and Glamour}

Celebrities are significantly represented across the website. We identified 35 $(n=35)$ different celebrities featured on 25 webpages. Most prominently so were US actor Leonardo DiCaprio (8), prince Albert II of Monaco (6), US actors Adrian Brody (4) and Cuba Gooding Jr (4), Russian model Irina Shayk (4), UK socialite Lady Victoria Hervey (4) and UK sport celebrity Louise Hazel (4). The celebrities mainly originate from the domains of film, royalty, sport and business and are predominantly American (12) and British (5). This apparent Anglo-Saxon dominance corresponds to a wider tendency throughout celebrity culture (Panis and Van den Bulck 2014), yet can also be explained due to the fact that the website was scraped at a time when it focused on the (then most recent) races in the United States and Monaco. The latter also suggests the connection with Prince Albert II of Monaco. Celebrities talked primarily about Formula E and to a lesser extent about supporting ES and their own achievements in that respect. Although 
each issue was raised only once, celebrities specifically pointed to climate change, green technologies and Formula E's sustainability efforts. Celebrities such as Leonardo DiCaprio and Sir Richard Branson, both stakeholders of Formula E race teams, advocated the necessity to create more sustainable motor sport. This suggests that Formula $\mathrm{E}$ attributes value to celebrities and uses them as a platform to further exposure of ES in Formula E:

Celebs love [electric vehicles]: George Clooney, Scarlett Johansson, Tom Hanks and Leonardo DiCaprio all own electric vehicles, just like famous car fanatic Jay Leno. [...]. The World Health Organization estimates that each year more than 70 million people die due to air pollution - electric vehicles do not produce emissions (Formula E 2015).

The characteristics of celebrities as commodities affect their subsequent environmental activism and as such influences the notion of ES (Van den Bulck 2018). The presence of celebrities further fits within the second most prominent non-ES goal, namely the "Continuation of the Formula One jet-set lifestyle":

[...] the After-Party has delighted guests with sky bars, rooftop pools and incredible seafront villas. Featuring renowned sponsors such as Mumm, Diageo and Amura Capital together with celebrity guests such as supermodel Valeria Mazza, superstar DJ Erick Morillo [...] (Formula E 2015).

Clearly, the emphasis on glamour goes hand in hand with the presence of celebrities in Formula E's self-organizational representation.

\section{Promotion through Sport: Advertisements, Partners and Sponsors}

A final factor in relation to commodification is that of advertising. In total we found 910 display advertisements, made up of 12 different advertisements. Table 3 presents an overview of the different advertisements and their links. Each webpage featured up to five advertisements. Out of those 12 advertisements, eight advertisements were identified as originating from commercial partners with varying degrees of affiliation with Formula $\mathrm{E}$ and only one advertisement that referred to sustainability, i.e. DHL. The remaining four advertisements were identified as editorial advertisements of which two revealed an exclusive link to ES (Green Tips and Tip of the Day).

The category of editorial advertisements featured predominantly "Green Tips" and, to a lesser extent, "Tip of the Week" and "Change your Light", which invited the public to consult Formula E's designated sustainability webpage containing simple and everyday efficiency- and sustainability enhancing tips and tricks. The remainder of this category involved a word cloud advertisement with the purpose of enhancing navigating the website. 
Table 3. Advertisements

\begin{tabular}{|c|c|c|c|c|c|c|c|}
\hline & Adverts & $\begin{array}{l}\text { Web- } \\
\text { pages }\end{array}$ & $\begin{array}{l}\mathrm{ES} \\
\text { link }\end{array}$ & $\begin{array}{l}\text { Partner } \\
\text { link }\end{array}$ & $\begin{array}{l}\text { Auto- } \\
\text { motive } \\
\text { link }\end{array}$ & $\begin{array}{c}\text { Motor } \\
\text { sport/ } \\
\text { FE } \\
\text { link }\end{array}$ & $\begin{array}{l}\text { Safety } \\
\text { Link }\end{array}$ \\
\hline \multirow{8}{*}{$\begin{array}{l}\text { COMMERCIAL } \\
\text { ADVERTISEMENTS } \\
\text { (TOTAL: 825) }\end{array}$} & $\begin{array}{l}\text { FIA Golden } \\
\text { Rules }\end{array}$ & 194 & & $\mathrm{X}$ & $\mathrm{X}$ & & $X$ \\
\hline & $\begin{array}{c}\text { Michelin } \\
\text { Golden Rule } \\
4 \\
\end{array}$ & 191 & & $\mathrm{X}$ & $\mathrm{X}$ & & $X$ \\
\hline & TAG Heuer & 86 & & $\mathrm{X}$ & & & \\
\hline & Renault ZE & 78 & & $\mathrm{X}$ & $\mathrm{X}$ & & \\
\hline & $\begin{array}{l}\text { Michelin } \\
\text { R\&D }\end{array}$ & 73 & & $\mathrm{X}$ & $X$ & & \\
\hline & BMWi & 70 & & $X$ & $\mathrm{X}$ & & \\
\hline & Qualcomm & 69 & & $\mathrm{X}$ & $\mathrm{X}$ & $\mathrm{X}$ & \\
\hline & DHL & 64 & $\mathrm{X}$ & $\mathrm{X}$ & & $\mathrm{X}$ & \\
\hline \multirow{4}{*}{$\begin{array}{l}\text { EDITORIAL } \\
\text { ADVERTISEMENTS } \\
\text { (85) }\end{array}$} & Green Tips & 69 & $\mathrm{X}$ & & & & \\
\hline & Word cloud & 13 & $\mathrm{X}$ & $\mathrm{X}$ & $\mathrm{X}$ & $\mathrm{X}$ & $\mathrm{X}$ \\
\hline & $\begin{array}{l}\text { Tip of the } \\
\text { Week }\end{array}$ & 2 & $\mathrm{X}$ & & & & \\
\hline & $\begin{array}{c}\text { Change your } \\
\text { Light }\end{array}$ & 1 & $X$ & & & & \\
\hline TOTAL & 12 & 910 & 5 & 9 & 7 & 3 & 3 \\
\hline $\begin{array}{l}\text { MICHELIN ADVERT } \\
\text { COMBINATION }\end{array}$ & 2 & 264 & I & $\mathrm{X}$ & $\mathrm{X}$ & I & $X$ \\
\hline
\end{tabular}

Source: Author.

Out of all 12 advertisements, two commercial (Qualcomm and DHL) and one editorial (Word Cloud) advertisement showed an obvious link with Formula E. Five advertisements make a link with ES but only one (DHL) of these is commercial. The editorial advertisements "Green Tips", "Tip of the Week" and "Change your Light" function as links to the sustainability webpages and exclusively featured eco labels such as "Energy", "Water", "Lifestyle" and "Waste" which were not part of any other editorial or commercial advertisements. Figure 2 shows some "Green Tips" with accompanying eco-labels.

The editorial advertisements featured in the same location, though less frequently, as the commercial advertisements. This dominance of commercial advertising space over ES allocated advertising space is in accordance with a main pattern of sport in general becoming an "adjunct of the advertisement industry" (Boyle and Haynes 2009: 45). The omnipresence of display advertisements, team logos and corporate/ partner logos on a vast majority of webpages further exposes the commodification of Formula E.

"Partners" operated frequently in conjunction with the theme of ES. Companies from the car industry (Renault, Dallara, BMW) to banking (Visa, Julius Bär) and green technologies (SMEG, GreenPower) appear keen to be associated with Formula $\mathrm{E}$ and its efforts in terms of ES, education and charity. In this sense, Formula E provides a means to communicate an organization's environmental CSR aspirations and activities to website visitors as well as its 
commitment to stakeholders (Trendafilova et al. 2013). Political support for the actions and efforts of Formula $\mathrm{E}$ was mostly related to the presence of a local politician or royalty such as, for example, Prince Albert II of Monaco, who showed his support for Formula E by stating that Monaco was proud to welcome the first Formula E race in Europe (Formula E 2015).

Figure 2. Partial View of the "Green Tips" Webpage with Accompanying Eco Logos (Energy, Water, Waste and Lifestyle)

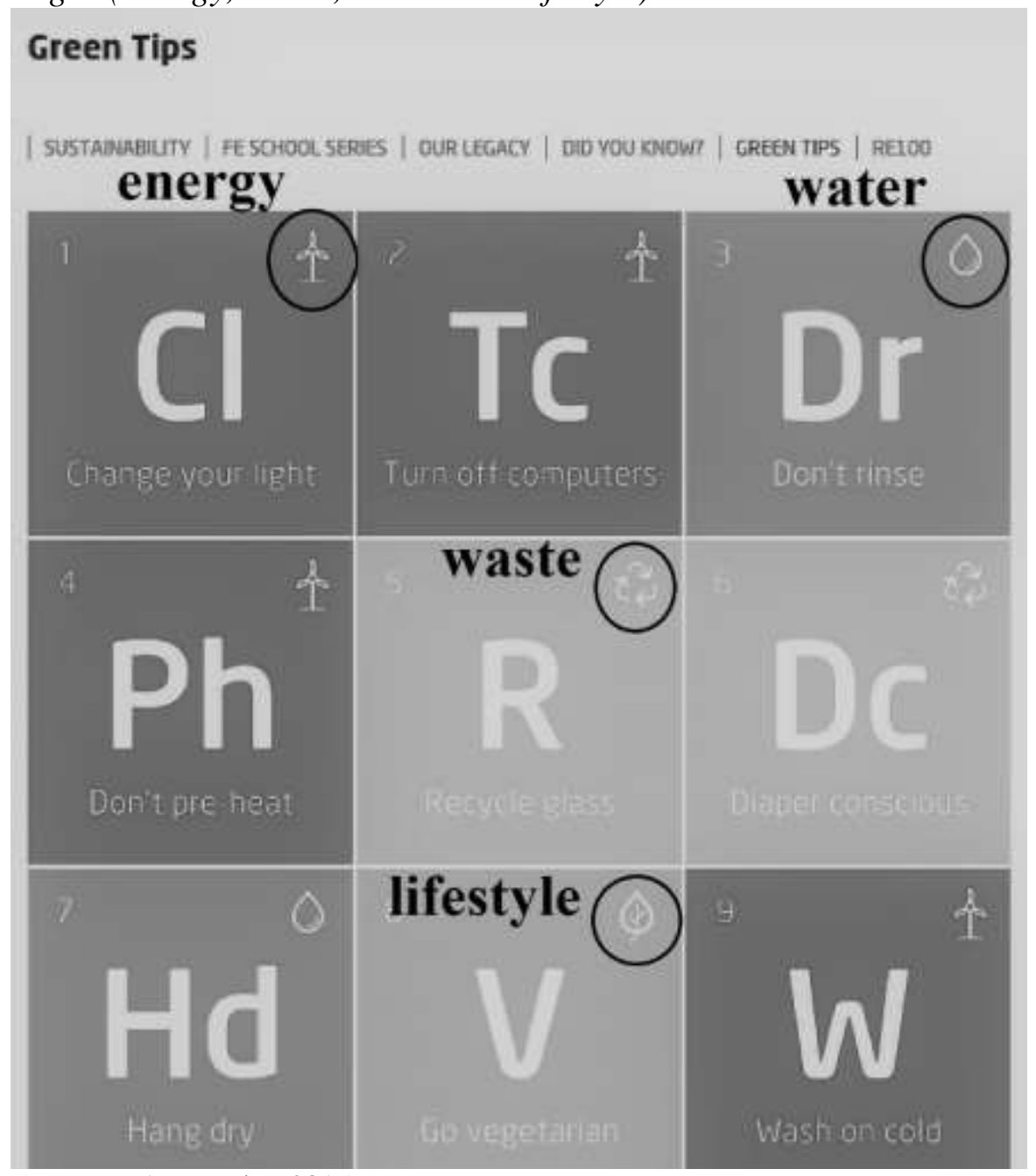

Source: FIAFormulaE 2015.

Of particular interest were also the efforts by Julius Bär and TAG Heuer to convince the Swiss government to soften the ban on racing following the 1958 tragedy at Le Mans by means of the advantages associated with Formula E (Law change opens door 2015). This reflects a key element in power relations as permission is given by governments on the basis of ES and safety which, undoubtedly, holds significant promotional advantages for Switzerland as much as for Formula E. 


\section{Discussion and Conclusion}

Formula E seems to, at least in part, have succeeded in presenting itself as an organization that has combined a relatively profound ES approach without compromising on values and traditions commonly associated with motor sport. It needs to be said that the emphasis does rest with the latter. This reveals that Formula E has picked up on the need for motor sport to become more sustainable whilst at the same time making use of the marketing and educational advantages that come with it, as suggested by Smith and Westerbeek (2004). In accordance with Lester's (2010) claim that environmental support from celebrities is commonly used by companies, celebrity support for Formula E's ES efforts form part of a larger marketing strategy that aims to mobilize existing support (cf. Lester 2010) as well as notify new audiences. Further, Formula E also uses celebrities to fulfill the more traditional role associated with motor sport, namely contributing to the aspect of glamour. Yet, although Formula E associates itself with glamour, it does not achieve the same level as for Formula One (Sturm 2014), which could be down to two reasons. First, as an emerging series Formula E does not yet enjoy the same level of stability, heritage or well-knownness as Formula One does. Second, this might be an intentional result by Formula $\mathrm{E}$ to avoid criticisms or stigmas commonly associated with Formula One, such as for example "circus" or "glamour spectacle" (Evans 2013, Sturm 2014). In any case, and as shown, the fact that Formula E links its own popularity to the sort of celebrities it attracts reveals that it does value exclusivity greatly. Consequently, this association with celebrities and glamour stimulates the commodification value of ES and is further extended by means of commercial and "green" advertising that incorporates eco labels, display advertisements and corporate logos. As we revealed, Formula E accommodated a substantial presence of commercial or corporate advertising. The reason for this is that Formula $\mathrm{E}$ has sacrificed its media rights revenue by making Formula E accessible free-of-charge to all broadcasters with the aim of achieving the highest level of public exposure possible (Chauhan 2015). Much as is the case for other sports that do so, and as can be witnessed from our analysis, this means that Formula $\mathrm{E}$ is largely driven by corporate revenue through advertising (Boyle and Haynes 2009). By adding editorial (ES) advertisements, Formula E creates two advantages. First, advertising companies are associated with ES, even if their advertisement does not incorporate an ES reference. Secondly, Formula E is able to "advertise" its own ES beyond the designated "sustainability" section on the website and, as such, present itself as a motor sport series that substantially integrates ES as a core ethos (Dingle 2009).

On the basis of our analysis we can conclude that Formula E's selfrepresentation in terms of ES, to a certain extent, can be considered to be a form of greenwashing by not being able to realize fully what it sets out to do in the first place (Platell 2010, Miller 2016). For one, the Formula E website does not properly indicate whether the much reduced carbon footprint from race cars outweighs the extra emissions from building temporary race tracks in cities as opposed to using existing race tracks. As such, and similar to Miller's (2016) findings in relation to greenwashing in Formula One and FIFA, the total ecological 
impact of Formula $\mathrm{E}$ was not fully considered. Where it is normally easier for businesses to spin stories rather than to significantly change resulting in environmental CSR being nothing more than a PR exercise or even a smokescreen (Karlsen 2011), it does seem that by means of external audits and action plans Formula E does aim to bring across its case more profoundly and attempts to present an image of being a catalysator for more environmentally sustainable vehicles. In that respect, and from a macro perspective on motor sport as a whole, Formula E could also be seen as a first step in profound change in motor sport governing behaviour.

Similarly, we also need to acknowledge that ES in Formula E does not escape the grasp of commodification considering Formula $\mathrm{E}$ is first and foremost a professional business aimed at making profit to which elements such as celebrities, glamour and gamification, most notably by tapping into eSports, contributes to in different ways and measures. At the same time, we see efforts to raise awareness in terms of ES. As our analysis revealed, the use of certain games on the website do fit an educational purpose. However, Formula E's most significant contribution in this respect remains that it, possibly for the first time ever in motor sport history, embraces ES as a major topic in its organizational identity.

As the first of its kind, this unicity of this study is that it looked specifically at the notion of ES in the self-representation of motor sport during a time in which ES has reached levels of global acknowledgement and action, both public and political in nature, never seen before. We do acknowledge the limitations in terms of generalization and exclusiveness of this particular case study, which was restricted to just a single website at one specific moment in time. Yet, we do believe this study's findings raises relevant empirical insights that allow to further the understanding of concepts such as the commodification of ES and greenwashing, especially so in motor sport. and contributes to an area of increasing academic interest. The unicity of Formula $E$ as a field where commercial motor sport and ES crucially come together further contributes, if only for the highly likelihood that more such seemingly "unusual" collaborations might arise.

\section{References}

Altheide DL (1996) Qualitative Media Analysis. Thousand Oaks, CA: Sage.

Boyle R, Haynes R (2009) Power Play: Sport, the Media and Popular Culture. Edinburgh: Edinburgh University Press.

Bryman A (2012) Social Research Methods. Oxford: Oxford University Press.

Chauhan E (2015 August) Racing for pole position. Sport Business International, 32-39.

Corbett JB (2006) Communicating Nature: How We Create and Understand Environmental Messages. Washington, DC: Island Press.

Corporate Watch (Ed) (2006) What's wrong with corporate responsibility? Corporate Watch Report 2006. Oxford.

Cox R (2012) Environmental Communication and the Public Sphere. London: Sage.

Cox R, Pezzullo PC (2015) Environmental Communication and the Public Sphere. London: Sage. 
Crabbe T, Brown A (2004) You're not welcome anymore: the football crowd, class and social exclusion. British Football and Social Exclusion, 109-124.

Dart J (2014) New media, professional sport and political economy. Journal of Sport and Social Issues 38(6): 528-547.

Deterding S, Sicart M, Nacke L, O'Hara K, Dixon D (2011) Gamification. using gamedesign elements in non-gaming contexts. In CHI'11 Extended Abstracts on Human Factors in Computing Systems. ACM, 2425-2428.

Dingle G (2009) Sustaining the race: a review of literature pertaining to the environmental sustainability of motor sport. International Journal of Sports Marketing and Sponsorship 11(1): 75-91.

Dorsey E, Steeves H, Porras L (2004) Advertising ecotourism on the internet: commodifying environment and culture. New Media \& Society 6(6): 753-779.

European Commision (2011) Corporate Social Responsibility: a new definition, a new agenda for action [Memo]. Retrieved from https://bit.ly/2SftfOY.

Evans CA (2013) The Media Representation of Formula One as 'Spectacle': Constructing Sport as a Live Mediatised Event. Doctoral Thesis. Cardiff University.

Fairley S, Tyler B, Kellett P, D'Elia K (2011) The Formula One Australian grand prix: Exploring the triple bottom line. Sport Management Review 14(2): 141-152.

Federation Internationale de l'Automobile (2016) Retrieved from https://bit.ly/1Vrretm. [Accessed 21 May 2016].

Formula E (2015) Sustainable Mobility. [online]. Retrieved from https://bit.ly/19B6Wpx. [Accessed 26 November 2015].

Gläser J, Laudel G (2013) Life with and without coding: two methods for early-stage data analysis in qualitative research aiming at causal explanations. Forum Qualitative Sozialforschung, 14, 2. Retrieved from https://bit.ly/2DYG4Ka.

Haase-Reed A, Kushin M, Koeppel T (2007) Framing the ELF: an exploration of media representation and self-representation of a social movement organization. Annual meeting of the NCA $93^{\text {rd }}$ Annual Convention.

Hall S, Evans J, Nixon S (Eds) (2013) Representation. London: Sage Publications.

Hassan D, and O'Kane P (2011) The great race across the Sahara: a history of the Paris to Dakar rally and its impact on the development of corporate social responsibility within motor sport. The International Journal of the History of Sport 28(2): 268-280.

Jakubowska L (2001) Hermeneutic photography analysis in researching virtual selfpresentation. In Jakubowska L (Ed). Methods and Techniques of Cyberspace Research Theory and Practice. Legnica, 87-98.

Karlsen OA (2011) Racing Towards Sustainability? Formula 1 and Corporate Social Responsibility. Master's Thesis. Norwegian University of Science and Technology, Norway. Retrieved from https://bit.ly/2ReXmG6.

Krippendorf K (2004) Reliability in content analysis: Some common misconceptions and Recommendations. Human Communication Research 30(3): 411-433.

Law Change opens door for Formula E race in Switzerland (16 March 2015) Autosport. Retrieved from https://bit.ly/2r4ply9.

Lester L (2010) Media And Environment: Conflict, Politics And The News. Cambridge: Polity Press.

Miller T (2016) Greenwashed sports and environmental activism: Formula 1 and FIFA. Environmental Communication 10(6): 719-733.

Mohr LA, Webb DJ, Harris KE (2001) Do consumers expect companies to be socially responsible? The impact of corporate social responsibility on buying behavior. Journal of Consumer Affairs 35(1): 45-72.

Mosco V (2009) The Political Economy of Communication. London: Sage. 
Panis K, Van den Bulck H (2014) In the footsteps of Bob and Angelina: Celebrities' diverse societal engagement and its ability to attract media coverage. Communications 39(1): 23-42.

Platell L (2010) Rethinking Communication Strategies in The Automotive Industry: The Influence of Environmental Claims on Manufacturers' Communication Strategies. Germany, Erfurt: Lambert Academic Publishing.

Rojek C (2006) Sports celebrity and the civilizing process. Sport in Society 9(4): 674-690.

Roy DP, Goss BD, Jubenville C B (2010) Influences on event attendance decisions for stock car automobile racing fans. International Journal of Sport Management and Marketing 8 (1-2): 73-92.

Russo V, Milani L, Re A, Crescentini A, Sciangula C (2012) The sustainability and the role of the mass media: Representation, values and behaviours among consumers in Italy. In IEPDR (Ed). Singapore: IACSIT Press, 71-77.

Segal D (2014 October 10). Behind League of Legends, E-Sports's Main Attraction. New York Times. Retrieved from https://nyti.ms/2PW79UX. [Accessed 26 November 2015].

Simon FL (1995) Global corporate philanthropy: a strategic framework. International Marketing Review 12(4): 20-37.

Smith A, Westerbeek H (2004) The Sport Business Future. Palgrave Macmillan, Basingstoke.

Sturm D (2014) A glamorous and high-tech global spectacle of speed: Formula One motor racing as a mediated, global and corporate spectacle. In Fletcher N, McCullough, Dashper K (Ed) Sports Events, Society and Culture, TRoutledge, London, 68-82.

Sturm D (2011) Masculinities, affect and the (re) place (ment) of stardom in Formula One fan leisure practices. Annals of Leisure Research 14(2-3): 224-241.

Swithinbank R (2014, July 1). Electric avenue. The Times. Retrieved from https://bit.ly/ 2r5bl5I. [Accessed 2 May 2015]

Switzer J (1997) Green Backlash: The History and Politics of The Environmental Opposition in The US. Lynne. Rienner Publishers.

Trendafilova S, Babiak K, Heinze K (2013). Corporate social responsibility and environmental sustainability: Why professional sport is greening the playing field. Sport Management Review 16(3): 298-313.

Turner B (2005) The Pits: The Real World of Formula One. Atlantic Books.

UNCTAD (2010) Investment and enterprise responsibility review. Retrieved online from: https://bit.ly/2TMWKsP.

United Nations (1988) Our common future. Brundtland Report. Oxford University Press.

Van Couvering E (2004, July) New media? The political economy of Internet search engines. Paper presented at the IAMCR. Porte Alegre, Brazil.

Van Den Bulck H (2018) Celebrity Philanthropy And Activism: Mediated Interventions In The Global Public Sphere. London, UK: Routledge. 